\title{
Evaluation of the drainage system of Zagros Basin (Greater Zab River, northern Iraq) and insights into tectonic geomorphology
}

\author{
Ziyad Elias $^{1}$ • Varoujan K. Sissakian ${ }^{2} \cdot$ Nadhir Al-Ansari $^{3}$ (D) \\ Received: 5 March 2018 / Accepted: 31 October 2020 / Published online: 7 November 2020 \\ (C) The Author(s) 2020
}

\begin{abstract}
Geomorphological evaluation was carried out for three drainage basins named Hareer, Dwaine, and Hijran, which are tributaries of the Greater Zab River in the northern part of Erbil Governorate, the Iraqi Kurdistan Region, north Iraq. The exposed rocks in the three basins are mainly clastic rocks (sandstone, claystone, and conglomerate, with subordinate gypsum and limestone beds). However, in the uppermost parts of the basins, thick and massive carbonate rocks are exposed. Tectonically, the three basins are located in the Low Folded and High Folded Zones, which belong to the Zagros Fold-Thrust Belt. The main aim of the current study is to deduce the tectonic activity of the area occupied by the studied three basins. We have used and interpreted Radar Topography Mission (SRTM) data to perform the geomorphological evaluation. Different geomorphological indices and forms were used to deduce the tectonic activity of the area occupied by the three basins. Accordingly, seven orders of streams were identified in the three basins. The number of the streams with low order (i.e., 1) joining with higher order (i.e., 6 and 7) is considerably higher in the three basins. The Hat values of the three basins are 12,971, 10,479, and 7014 in Hareer, Dwaine, and Hijran basins, respectively. The values of hierarchical anomaly index $(\Delta \mathrm{a})$ of the three basins are 1.87, 1.35, and 2.37 in Hareer, Hijran, and Dwaine basins, respectively. It was observed that the shape of Hareer and Shakrook anticlines has a significant impact on the main trunk of the channel. Therefore, when an anticline and syncline are close to each other (due to thrust faulting), then the hierarchical anomaly increases because the river trunk receives a lot of first-order streams, e.g., in Dwaine and Hijran basins. The lateral growth in the eastern part of Safin anticline had caused increasing of the $\Delta \mathrm{a}$. The increased hierarchical anomaly index is attributed to the existence of faults and lineaments, which represent weakness zones. The hypsometric curves of the three basins have a typical shape of old stage with rejuvenation in their central and terminal portions which is changed into mature stage, most probably due to the local uplift which is caused by normal, thrust, and strike-slip (oblique) faults which exist in the study area and the near surroundings. The Bs and Hat values in Hareer, Dwaine, and Hijran basins indicate that the basins exhibit low, medium, and high tectonic activity, respectively.
\end{abstract}

Keywords Active tectonics · Geomorphic indices · Fluvial networks $\cdot$ Zagros Mountain · Iraqi Kurdistan

Editorial Responsibility: Stefan Grab

Nadhir Al-Ansari

nadhir.alansari@1tu.se

Varoujan K. Sissakian

f.khajeek@ukh.edu.krd; varoujan49@yahoo.com

1 Geomorphic Researcher, Hannover, Germany

2 Department of Natural Resources Engineering \& Management, University of Kurdistan Hewler, Erbil, KRG, Iraq

3 Lulea University of Technology, Lulea, Sweden

\section{Introduction}

The stream network is a good substitute indicator for the landform organization, and the density of the lowest-order streams clearly delimits the landforms (Cudennec and Fouad 2006). Moreover, the morphometric indices are tools for analyzing the drainage systems and evaluating tectonic activity in a given area (Keller and Pinter 2002). In tectonically active areas the like Iraqi Kurdistan Region, the drainage basins can give good indication for the activity of the tectonics in a concerned area, especially when the area is located nearby to boundaries of tectonic plates. The Iraqi Kurdistan Region forms the extreme northeastern part of the Arabian Plate which is in collision with the Eurasian Plate with convergent type of plate 
tectonic boundary (Fouad 2012). Due to the collision, which is still active the Zagros Thrust-Fold Belt through which the Zagros Foreland is located is formed including tens of anticlines of different type and sizes, almost all of them include drainage basins that show reflection to the tectonic activity in different forms and intensities.

Three drainage basins were studied, they are surrounded by four main anticlines called Hareer, Shakrook, Safin, and Pirmam, all are located in the Zagros Fold-Trust Belt (Fouad 2012) (Fig. 1). This study was performed because the drainage systems including rivers, streams, and valleys are the main features of any drainage basin and the quantitative study of a drainage system gives significant ideas about the tectonic activity of the basin area (Burbank and Anderson 2001, and Keller and Pinter 2002). The hierarchical organization of the drainage networks of three basins were studied and analyzed by means of bifurcation ratio (Horton 1945; Strahler 1952). Both workers presented new concepts in the analyzing of the drainage system by means of stream ordering. However, in order to have better definition of the hierarchical organization of a drainage system, Avena et al. (1967) introduced the bifurcation index (R), hierarchical anomaly number (Ha), and hierarchical anomaly index $(\Delta$ a). Avena et al. (1967) have used the parameters of the hierarchy of a drainage network, such as the bifurcation ratio $(\mathrm{Rb})$ and bifurcation index $(\mathrm{R})$ in recognizing of some poorly organized hydrographic networks in Italy.

Recently, many published studies have dealt with the morphometric characteristics of drainage system of many basins and sub basins in different parts of the globe (Tatar et al. 2002; Ramsey et al. 2008; Guarnieri and Pirrotta 2008 and Bahrami 2013). Burbank and Anderson (2001) studied the relationships between landslides and drainage network and concluded that geomorphological analysis of the drainage network has been performed to evaluate the influence of landslide processes on morphometric properties of the drainage network. Bahrami (2013) analyzed the anomaly of the drainage system of Zagros Basin in Iran and stated how the shape of the anticline has an impact on the growth of the streams. Moreover, Santangelo et al. (2013) focused on the impact of the fault system on the order of the stream and studied the effect of the tectonics on stream ordering.

Many concepts (example Ramsey et al. 2008; Deffontaines and Chorowicz 1991; Jackson et al. 1998; Sung and Chen 2004; Reif et al. 2012 and Delcaillau et al. 2006) were adopted in this study; they explain the effect of the vertical and horizontal motions of crustal rocks and erosional processes in the development of landscapes in tectonically active areas and their role in shaping of the studied three basins. Other evidence for active tectonics can be deduced from drainage pattern and anomaly analysis (Talling and Sowter 1999; Jamieson et al. 2004; Zhang et al. 2006; Bretis et al. 2011; Devi et al. 2011 and Simoni et al. 2003; Oberlander. 1985). In the studied four folds, indicators for fold growth and segmentations which can be preserved as geomorphological features were checked and indicated from satellite images and were confirmed in the field. Among the geomorphological features are fork-shaped and curved valleys which are good evidence for tectonically active drainage basins at different areas. For example, at Zagros Range in Iran (Bahrami 2013), at Pirmam and Safeen anticlines in north Iraq (Bretis et al. 2011), and at Qara Dagh anticline in northeast Iraq (Sissakian et al. 2018). We have noticed such valleys in the anticlines of the studied area. Whaleback-shaped anticlines also were used as an indicator for tectonically active folds in the active and young Zagros Folded-Thrust Belt (Bretis et al. 2011); they also noticed that the anticlines are with large variation of fold dimensions. This indication was also used as one of the parameters in deducing the lateral growth of Qara Dagh anticline in northeast Iraq (Sissakian et al. 2018). We have noticed the same morphological form in Hareer anticline.
Fig. 1 Satellite image facing NE showing the studied three basins and surrounding four anticlines

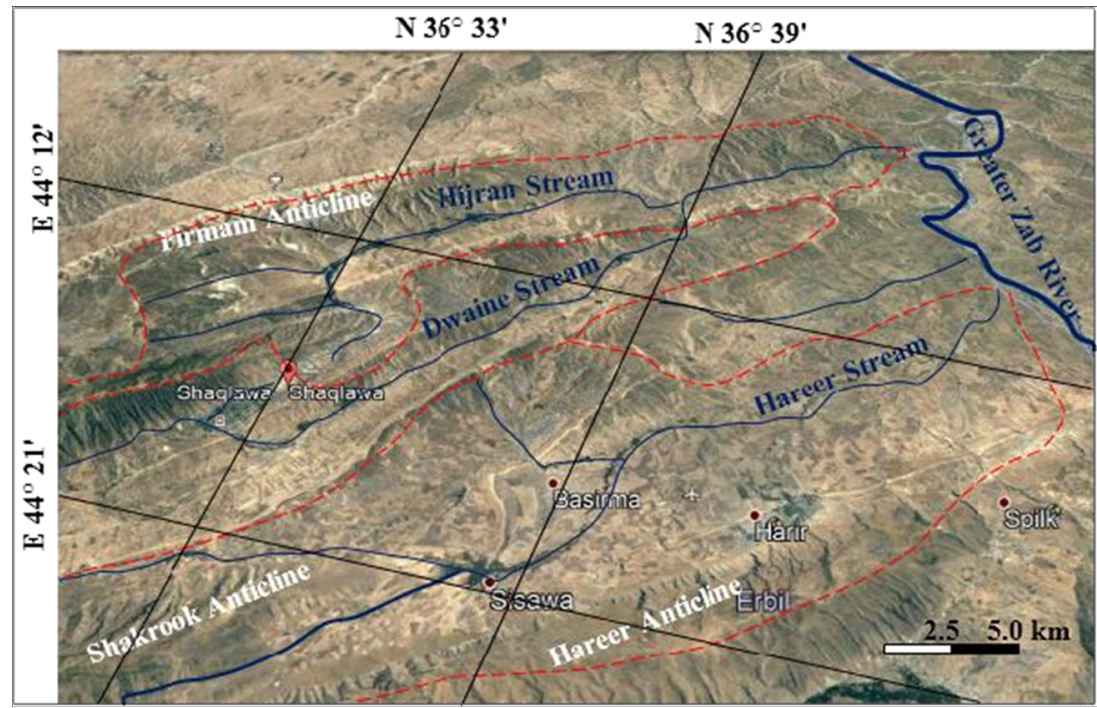


The main aim of this study is to evaluate the tectonic activity of the studied drainage basins, Hareer, Dwaine, and Hijran streams which drain to the Greater Zab River. To achieve the aim of the current study, different geomorphological and structural tools were used by means of using Arc GIS techniques and Radar Topography Mission (SRTM) images, and depending on different opinions of many authors and aspects as mentioned above. The study area is located in the central part of north Iraq (Figs. 1 and 2), which is a mountainous area with high and long mountain chains. Majority of them represent anticlines with very rugged topography. The majority of studied area is located within the High Folded Zone of Iraq (Fouad 2012).

\section{Data used and methodology}

For quantitative evaluation of a drainage system and its relevance to tectonic activity, three basins were selected between Low-Amplitude Mountainous Province and High-Amplitude Mountainous Province to evaluate their tectonic activity. In order to delineate the borders of the three selected basins in this study, SRTM image, which has a ground resolution of 3 arcsecond $(90 \mathrm{~m})$ and a vertical accuracy of approximately $10 \mathrm{~m}$, was used. This resolution allows identifying morphometric indices such as hypsometric curve, asymmetric factor (AF), and basin shape index (Bs). The coverage area and perimeter measurements of the three drainage basins (maximum and minimum elevations, mean elevations, outlet elevation, basin shape, total length, and drainage density) were carried out using the ArcGIS software.

For quantitative evaluation of the drainage system and its relevance to tectonic activity, three basins were selected between Low-Amplitude Mountainous Province and HighAmplitude Mountainous Province. The borders of basins in the study area were delineated using SRTM image. SRTM that has a ground resolution of 3 arcsecond $(90 \mathrm{~m})$ and a vertical resolution of approximately $10 \mathrm{~m}$ is used. This resolution allows identifying geomorphic indices. We have used the River tools software using SRTM images for identifying stream order. The ArcGIS software was used to obtain basin boundaries, areas, lengths and widths of basins, number of the orders, and also mapping of the stream order. Characteristics of the landform of the basins, such as the maximum, minimum, and mean elevations were obtained from SRTM. The stream orders were assigned following Strahler's ordering system (Strahler 1957). Then, stream length and the number for each order were calculated using the GIS technique. We have used Archydro in the Arc Map to identify the ordering stream. The first step is the Fill tool and next is flow direction. The
Fig. 2 Tectonic setting of the Arabian plate. Red arrows indicate plate motions in centimeters per year (After Abdulnaby 2018)

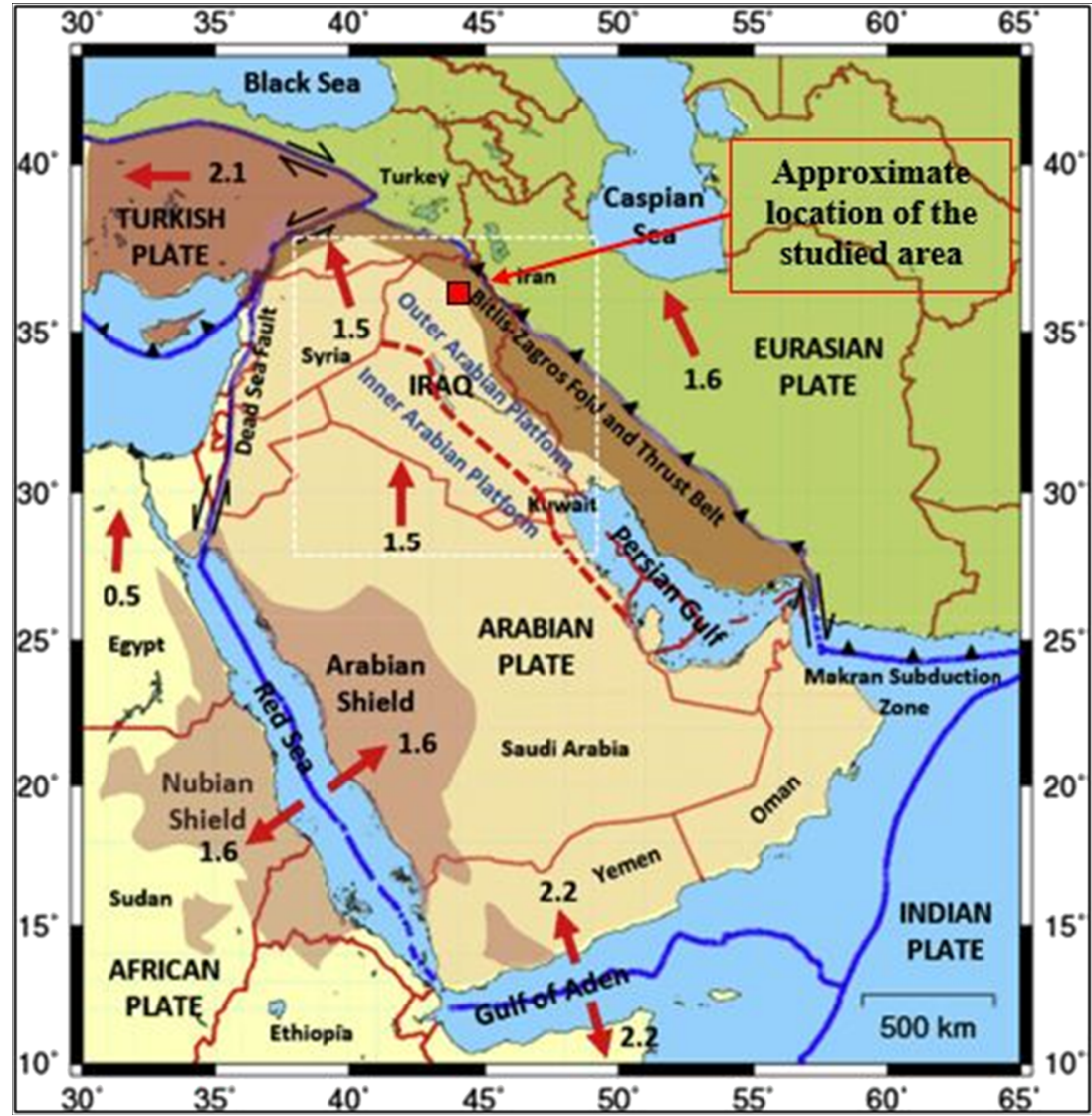


results of the Flow Accumulation tool were used to create a raster stream network; then by applying a threshold value, cells with a high accumulated flow were selected. Consequently, the stream junctions or paths $(\mathrm{i} \rightarrow \mathrm{j})$ were identified, and subsequently, the number of streams in each junction $(\mathrm{Nsi} \rightarrow \mathrm{j}$ ) was obtained.

Geological units and their areas were derived from 1:250,000-scale geological map. In order to study the effect of the tectonic activity on the drainage system and basins morphometry, fold segments and type of the fault were imposed on the SRTM image. Different data of tectonics, structural geology, geomorphology, and stratigraphy of the exposed rocks in the three basins were briefed using the best available data.

Field work was carried out in 2015 to check about anomalous streams and some structural features like faults and their effect on the drainage system. Moreover, some interesting features were photographed and added into the current text.

\section{Geological background}

The mountainous area in northern Iraq was classified into three physiographic provinces (Sissakian and Fouad 2012). The study area is located in the Low-Amplitude Mountainous Province and High-Amplitude Mountainous Province. The three basins are located between Hareer, Shakrook, Safin, and Pirmam anticlines (mountains)
(Fig. 3). Moreover, the basins include Hareer, Shakrook, and Safin synclines. Ten geological formations are exposed within these anticlines and synclines. They range in age from Cretaceous (Qamchuqa, Bekhme, Shiranish, and Tanjero formations) to the Tertiary age (Kolosh, Khurmala, Gercus, Pila Spi, Fatha, Injana, Mukdadiya, and Bai Hassan formations) (Sissakian 1997) (Fig. 4).

The major folds in the study area (Figs. 3 and 4) are (from the north to the south): Hareer anticline and syncline, Shakrook anticline and syncline, Safin anticline and syncline, and Pirmam anticline. Three streams flow in the troughs of the synclines, they are Hareer, Dwaine, and Hijran. The asymmetry of Hareer, Shakrook, and Pirmam anticlines are towards northeast, whereas the asymmetry of Safin anticline is towards the southwest. Therefore, the steep limbs are not the same in the all anticlines; the steep limbs have formed very deeply cut valleys (Fig. 5) which lead to the three basins. Different types of faults were mapped (Sissakian and Youkhanna 1979) like strike-slip, thrust, reverse, and normal faults, mainly parallel and/or oblique to the fold axes. Only some of the mapped faults are presented in the geological map (Fig. 4), due to the scale limitation. Apart from the main thrust fault which exists between Hareer and Shakrook anticlines and which has narrowed the original width of Hareer syncline; accordingly, narrowed the width of Hareer basin, the other faults have no significant effect on the studied three basins. This is attributed to the locations of the faults, which are mainly along the upper parts of the anticlines. However, locally, the streams are
Fig. 3 Shaded Relief with topographic contour (contour interval $250 \mathrm{~m}$ ) calculated from the SRTM Digital Elevation Model showing the names of the anticlines (mountains)

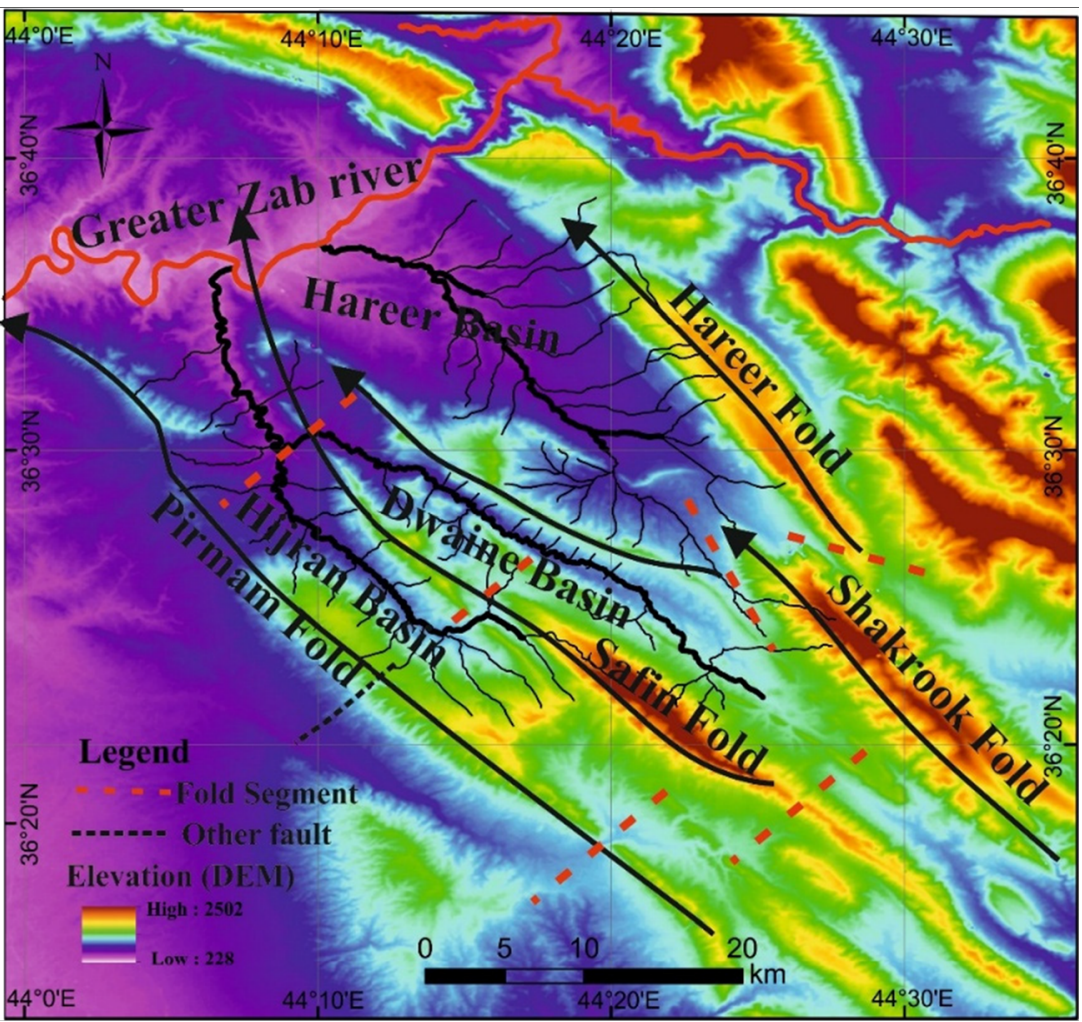


Fig. 4 Geological map of the study area (After Sissakian and Fouad 2014)

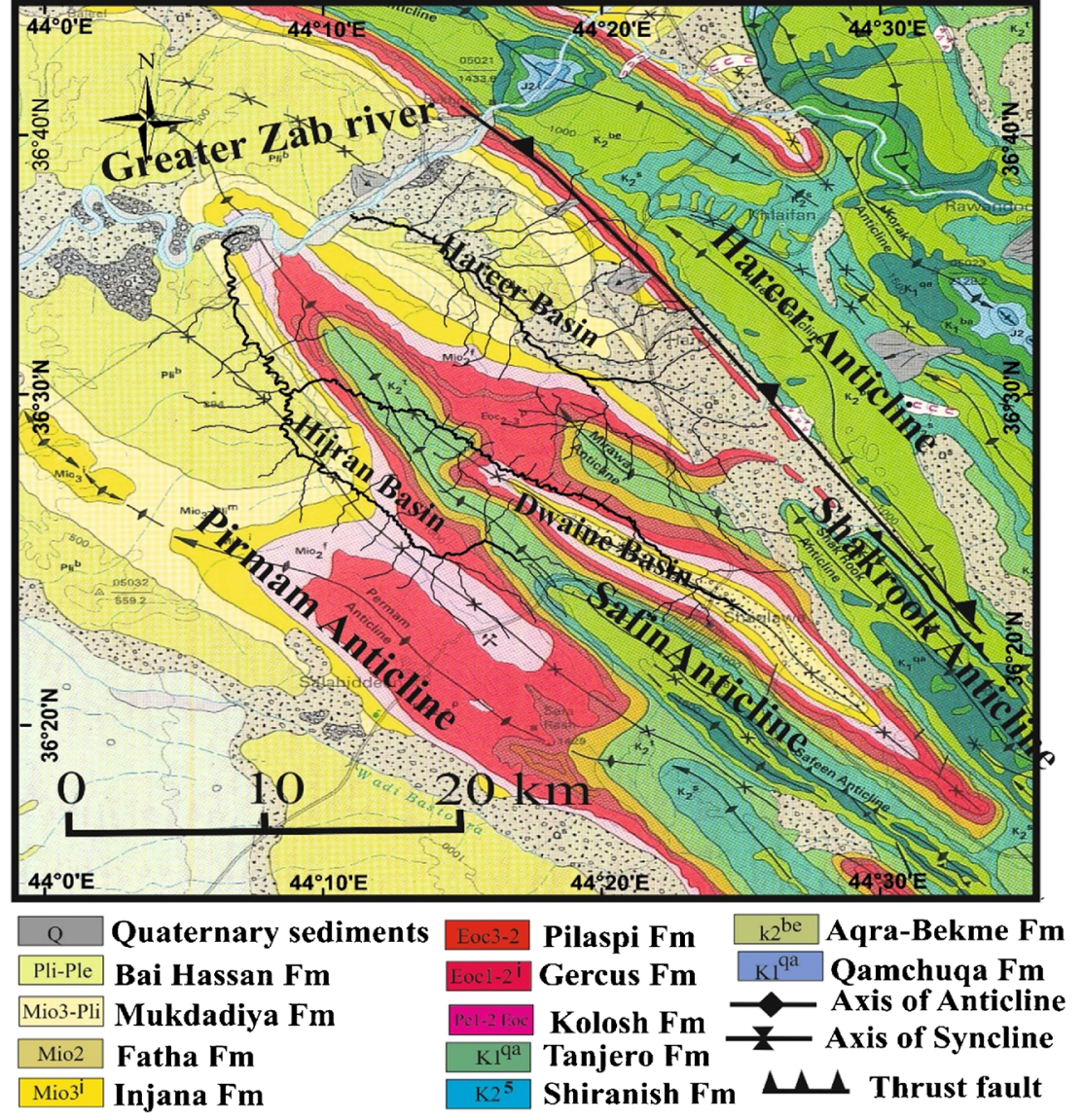

following the faults in the form of straight valleys and/or crossing some ridges (Fig. 6). Majority of the faults are located in Safin anticline being mainly parallel to the axis, which means that they are formed also due to the accumulated shear stresses.

All the mentioned anticlines are located in the High Folded Zone forming persistent mountains with rigged morphology, whereas the northwestern parts (plunge areas) of the synclines are located in the Low Folded Zone (Sissakian and Fouad 2014) (Fig. 4). The synclines form the main streams of the studied three basins. The syncline which is located between
Shakrook and Safin anticlines (Safin syncline) forms hanging syncline and occupying part of Dwaine basin.

The whole Arabian Plate in which the study area is located suffers from regional shortening rate of $1.5 \mathrm{~cm} /$ year (Abdulnaby 2018), whereas McQuarrie et al. (2003) have measured the convergence rate to be about $2-3 \mathrm{~cm} /$ year. However, this rate is certainly not uniform over all the plate, being more as moving near the collision area between the two plates (Arabian and Iranian). It is worth mentioning that different authors have calculated different shortening ratios from different parts of Iraq. The differences in the calculated

Fig. 5 General view of Hareer anticline. Note the deeply cut valleys and wide Hareer basin

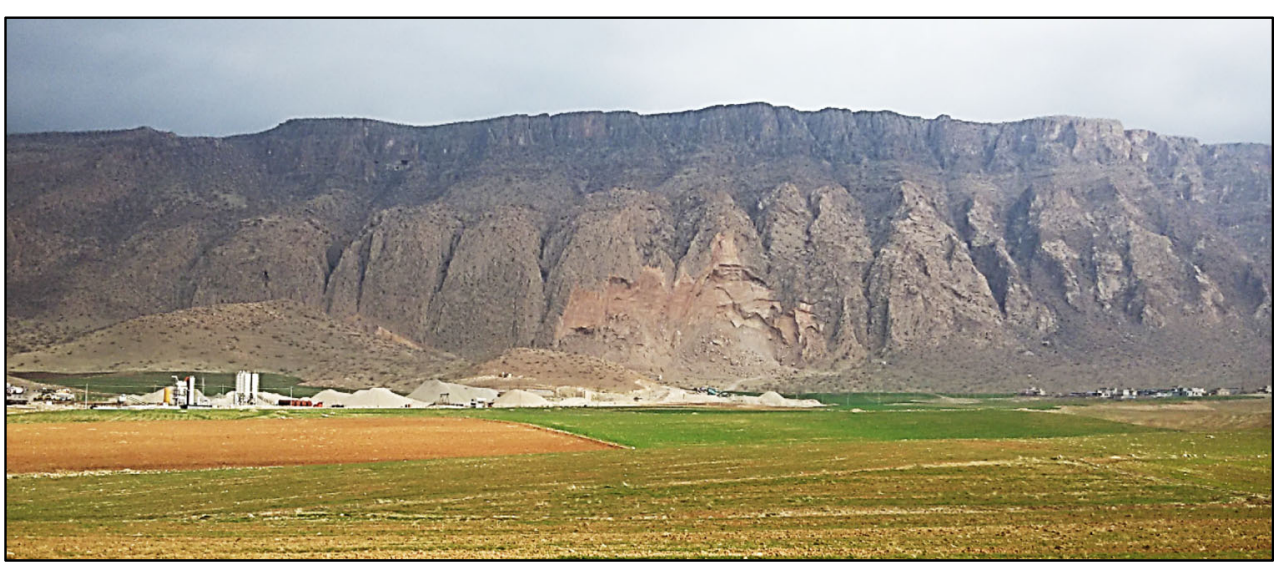


Fig. 6 Stream crossing ridges due to faults. Left Dawina stream crossing a ridge to merge with Hijran stream. Right Upper reaches of Dawina stream crossing a ridge in Safeen anticline through a fault. Shakrook anticline is in the background
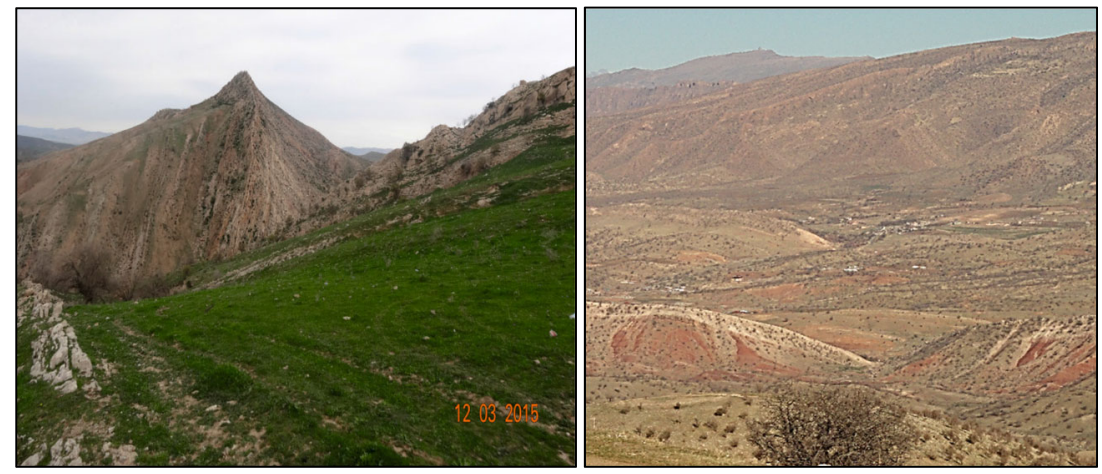

amounts depend on the procedure and accuracy of the calculation. Marouf (1999) calculated the shortening amount within the High Folded Zone, south east of the current study area to range between 8 and 27\%. Omer et al. (2015) estimated the partial shortening percentages of four anticlines northeast of the current study area within the High Folded Zone to range between 9.8 and 73.2\%. Al-Shali (1992) estimated the regional shortening in parts of the High Folded Zone and Low Folded Zone to be 15\%. Al-Brifkani (2016) determined the regional shortening of the High Folded Zone for six anticlines and noted that there is a decrease in the amount of the shortening from 37.5 to $4 \%$ southwestward.

The main trend of the folds in the current study area is NW-SE following the Zagros Range trend and is formed due the stresses exerted by the collision of Arabian and Eurasian (Iranian) plates (Fouad 2012) (Fig. 1). The accumulated shear stresses due to the collision have formed the existing faults; therefore, the main direction of the thrusting is towards southwest. Some of the thrust faults are extensive with tens of kilometers in length. Such as the thrust fault between Hareer and Shakrook anticlines, which had caused the disappearance of the synclinal axis between the two mentioned anticlines (Shakrook syncline) (Fig. 4).

It is worth mentioning that all the existing main streams are following mainly the troughs of the synclines, and some of them dissect the existing anticlines like Dwaine and Hijran streams cross Safin anticline forming water gaps (Fig. 4), mainly through existing faults. This means that the rate of the growth of the folds is almost the same rate of the stream incision; otherwise, wind gaps should be present in the anticlines (Keller and Pinter 2002; Ramsey et al. 2008).

The exposed geological formations (Fig. 4) in the studied basins are briefed hereinafter based on Sissakian and Youkhanna (1979) and Sissakian (1997). Those formations which are out of the basins are not mentioned:

1- Qamchuqa Formation (Lower Cretaceous): The formation consists of massive and very hard limestone, dolomite, and dolomitic limestone. Very locally, the formation forms the limits of the basins. The thickness of the exposed parts of the formation ranges 53-112 m.
2 Bekhme Formation (Upper Cretaceous): The formation consists of thickly bedded limestone and dolomite. The formation forms the carapace of the anticlines. The scarps of the formation form the limits of the basins. The thickness of the formation ranges 110-150 m.

3 Shiranish Formation (Upper Cretaceous): The formation consists of well-bedded, fairly hard marl beds overlain by thinly well-bedded and hard marl beds. The formation includes the fine tributaries of the basins, almost forming parallel drainage pattern. The thickness of the formation ranges $180-220 \mathrm{~m}$.

4 Tanjero Formation (Upper Cretaceous): The formation consists of soft claystone and sandstone. The formation locally forms the trough of the synclines including the fine tributaries of the basins, forming dendritic drainage pattern. The thickness of the formation ranges 230 $300 \mathrm{~m}$.

5 Kolosh Formation (Paleocene): The formation consists soft claystone and sandstone. The formation forms the trough of the synclines, including the middle tributaries of the basins, forming dendritic drainage pattern. The thickness of the formation ranges 110-180 m.

6 Gercus Formation (Paleocene-Eocene): The formation consists of soft claystone and sandstone. The formation forms continuous belts surrounding the syncline, including the middle tributaries of the basins, forming dendritic drainage pattern. The thickness of the formation ranges 130-150 m.

7 Pila Spi Formation (Eocene): The formation consists of hard limestone and dolomite. The formation forms continuous ridges in the form of flatirons surrounding the anticlines and locally in the trough of hanging synclines, including the fine tributaries in the form of parallel drainage pattern, and locally forms the synclinal valleys of the basins. The thickness of the formation ranges $100-120 \mathrm{~m}$.

8 Fatha Formation (Middle Miocene): The formation consists of claystone with rare gypsum and limestone beds in cyclic nature. The formation forms continuous belts surrounding the anticlines in the form of cuestas and hogbacks, including the middle tributaries in the form of 
trellis drainage pattern. The thickness of the formation ranges $120-150 \mathrm{~m}$.

9 Injana Formation (Upper Miocene): The formation consists of claystone and sandstone beds in cyclic nature. The formation forms cuestas and hogbacks and anticlinal ridges, including the middle tributaries of the basins in the form of trellis drainage pattern. The thickness of the formation ranges 330-400 m.

10 Mukdadiya Formation (Upper Miocene-Pliocene): The formation consists of claystone and sandstone beds in cyclic nature. The formation forms cuestas, hogbacks, and bad lands, including the middle tributaries of the basins in the form of trellis drainage pattern. The thickness of the formation ranges 430-500 m.

11 Bai Hassan Formation (Pliocene-Pleistocene): The formation consists of claystone and conglomerate beds in cyclic nature. The formation forms cuestas, hogbacks, and bad lands, including the fine and middle tributaries of the basins in the form of dendritic drainage pattern. The thickness of the formation ranges 300-500 m.

12 Quaternary Sediments: These are well developed, especially alongside the anticlines in the form of alluvial fans which form Bajadas. Moreover, terraces, slope sediments, and valley fill sediments are also developed in the basins, especially in the troughs. The thicknesses of the different types are variable depending on the type and morphological position. However, the thicknesses are less than $10 \mathrm{~m}$.

\section{Morphometric indices}

The morphometric indices are a tool for analyzing the landforms and evaluating the degree of tectonic activity in a given area (Alipoor et al. 2011; Elias 2015; El-Hamdouni et al. 2008). All geomorphic indices are influenced by the physical and mechanical properties of the exposed rocks in the studied area. The considered indices are the hypsometric curve, the Af, and the Bs indices. The indicated indices are mentioned hereinafter.

\section{Hypsometric curve}

The hypsometric curve represents the area distribution of relief and allows the identification of the evolutionary stage of the drainage basin (Bahrami 2013). The total area of the basin " $\mathrm{A}$ " is subdivided into sectors along the contour lines.

The curve (graph) represents the a/A ratio (relative area) on the $x$-axis,

where a is the area of the basin above the elevation $h$,

$h / H$ is the ratio (relative elevation) on the $y$-axis,

$h$ is the height of the contour line, and
$H$ is the maximum elevation of the basin.

A curve that is convex upward indicates a youth stage, a sigmoid curve indicates a mature stage, while a concaveupward curve indicates an old stage (Fig. 7).

\section{Asymmetric factor}

The asymmetric factor is defined as: $\mathrm{Af}=100 *(\mathrm{Ar} / \mathrm{At})$

where Ar denotes the basin area to the right (facing downstream) of the trunk stream, and At denotes a total area of the drainage basin.

The Af is classified into three classes: (class 1$)(\mathrm{Af}<35$ or Af $>65)$, (class 2$)(57<$ Af $<65$ or $35<$ Af $<43)$, and (class 3$)$ $(43<$ Af $<57)$, indicating high, medium, and low relative tectonic activity (Keller and Pinter 2002). In case of tectonic tilting, the values of Af are either greater or lower than 50 and the tributaries are present on the tilted side of the main growing stream. The latter is not the case for those located on the other side (Abrahams 1984).

\section{Basin shape index}

The basin shape index is defined as: $\mathrm{Bs}=\mathrm{Bl} / \mathrm{Bw}$ (Keller and Pinter 2002).

Where $\mathrm{Bl}$ is the length of a basin measured from the headwaters point to the mouth of the sub-basin, and Bw is the width of the sub-basin measured at its widest point.

The Bs includes three classes: (class 1) elongate basin with Bs $>4$, (class 2) semi-elongate basin with $3 \leq \mathrm{Bs}<4$, and (class 3 ) circular basin with $\mathrm{Bs}<3$. The three classes refer to high, medium, and low relative tectonic activity, respectively (Keller and Pinter 2002).

\section{Parameters of the hierarchy of the hydrographic network}

The calculation of these parameters defines the influence of the tectonics on the hydrographic network evolution. High values of these parameters indicate a poorly developed hierarchy and generally reflect active tectonics. The parameters used for this type of analysis are mentioned hereinafter:

\section{Hierarchical anomaly number}

The drainage system of a basin is subdivided into fluvial segments with increasing hierarchical order (Horton 1945). In Strahler's ordering system (Elias 2015), all headwater tributaries (nearest to the basin divide) are referred to as first-order streams. Two first-order streams produce a second-order stream, two second-order stream produce a third-order stream, and so forth. 

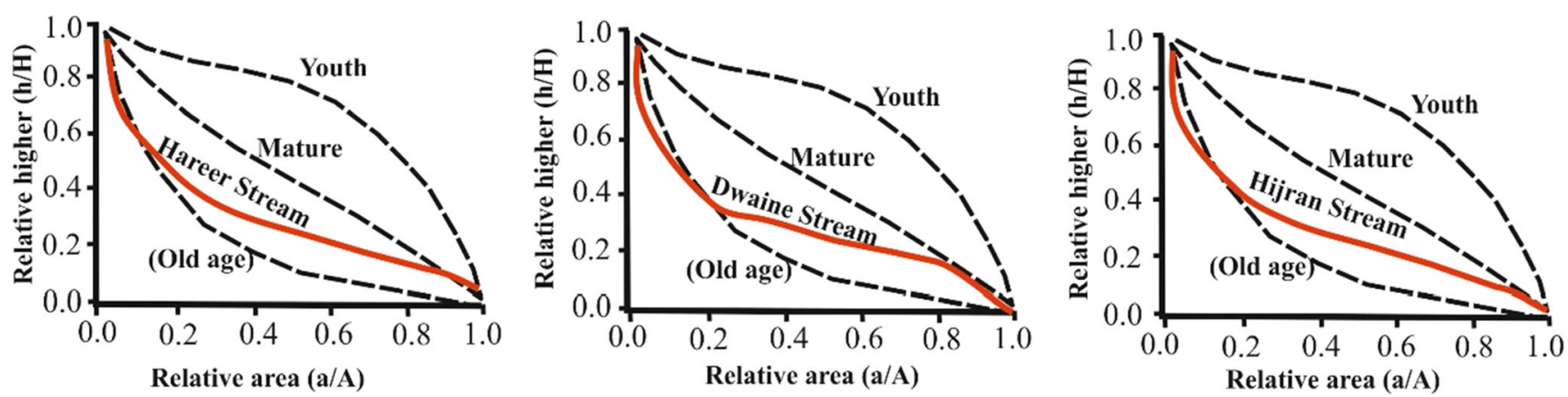

Fig. 7 Hypsometric curves of the three basins. Left Hareer. Middle Dwaine. Right Hijran

Streams of i-order that flow in streams of $i+2, i+3 \ldots \ldots$ etc. are anomalous stream junctions. Santangelo [11] defined the $\mathrm{Ha}$ as the minimum necessary number of the first-order segments to render the network perfectly hierarchical. However, using the Abrahams (Bull 2007) method, the Ha parameter can be calculated manually.

Different equations are introduced to calculate the hierarchical anomaly. In this study, the Hai equation, the number of every stream junction $(\mathrm{Hai} \rightarrow \mathrm{j}$ ), and hierarchical anomaly number of the whole basin (Hat) are calculated using the equation given by Guarnieri and Pirrotta (2008), which states that Hai $\rightarrow \mathrm{j}=2(\mathrm{j}-2)-2(\mathrm{i}-2)$.

By calculation of Hai $\rightarrow j$, the number of streams for each junction $(\mathrm{Nsi} \rightarrow \mathrm{j})$ of the three basin was obtained. Then, the hierarchical anomaly of the whole catchment (Hat) is calculated from the sum of $\mathrm{Hai} \rightarrow \mathrm{j}$ multiplied by Nsi $\rightarrow$ j (Guarnieri and Pirrotta 2008; Bahrami 2013), where $\mathrm{mNsi} \rightarrow \mathrm{j}$ is the number of the streams in each path. The higher the difference between $i$ and $j$, the higher is the hierarchical anomaly number (Bahrami 2013). After calculation of $\mathrm{Hai} \rightarrow \mathrm{j}$, the number of streams for each junction $(\mathrm{Nsi} \rightarrow \mathrm{j}$ ) of basin was obtained. The hierarchical anomaly number of the whole catchment (Hat) is calculated from the sum of Hai $\rightarrow \mathrm{j}$ multiplied by $\mathrm{Nsi} \rightarrow \mathrm{j}$ :

Hat $=\sum(\mathrm{Hai} \rightarrow \mathrm{j} \times \mathrm{Nsi} \rightarrow \mathrm{j})$

The $\Delta$ a parameter is sensitive to the effects of tectonic activity. In tectonically active mountains such as Zagros, the basins are elongated due to the effect of long anticlines and synclines (Avena et al. 1967), which is the same as in the studied area and near surroundings. Therefore, the value of the Hat index seems to be high in comparison with the N1 parameter; accordingly, the $\Delta$ a values of the basins are high.

\section{Hierarchical anomaly index}

The $\Delta \mathrm{a}$ is defined as the ratio of the Ha to the number of the first-order network (N1) (Abrahams 1984; Santangelo et al. 2013).

\section{Morpho-structure of the folds}

Based on the geomorphology of the folds and the direction of hinge lines, folds of the studied area are divided into a number of segments (Fig. 3). These segments probably have started as separate folds related to separate structural zones. Then, they propagated laterally with the evolution of deformation and linked to form one single fold. After linkage, the linked folds and their related thrusts begin to overlap. The topography in the linkage area becomes smoother after a long time from linkage (Talling and Sowter,1999). Thus, the geomorphic criteria that indicate lateral growth may progressively disappear. There are variations in the direction of hinge lines along the folds that display lateral growth (Bretis et al. 2011). This indicates changes in the stress direction with the time. Such linkage of many segments forming one long structure with many folds arranged in en-echelon pattern was recorded in Qara Dagh anticline (Sissakian et al. 2018), which is located southeast of the studied area. The lateral growth of the anticlines is clear in Shakrook, Safin, and Pirmam anticlines with increasing anomalous streams, especially in the orders 6 and 7 (trunk channel of Dwaine streams), and increasing anomaly in the orders 3 and 4 in Shakrook and Pirmam anticlines.

\section{Results}

The results of the acquired Bs values are assigned in Table 1; they indicate high, medium, and low relative tectonic activity in Hareer, Dwaine, and Hijran basins, respectively, as compared with the introduced three classes (Keller and Pinter 2002). We also have determined the Ha and $\Delta \mathrm{a}$ for the drainage system of the three studied basins, and the data are assigned in Table 1. Moreover, all the used necessary data which were used for calculation of different factors are summarized in Table 1.

The indicated hydrographic network of the studied three basins is represented according to the Strahler (1957) ordering system (Fig. 8). The network was indicated using the GIS technique (Archydro in the Arc Map). 
Table 1 Morphology of the basin, area, maximum elevation, outlet elevation, basin shape, total length, drainage density, and hierarchical anomaly index $(\Delta \mathrm{a})$

\begin{tabular}{llll}
\hline Morphology of basin & Hareer & Dwaine & Hijran \\
\hline Area $\left(\mathrm{km}^{2}\right)$ & 348.701 & 218.07 & 253.79 \\
Max elevation $(\mathrm{m})$ & 1500 & 2000 & 2000 \\
Outlet elevation $(\mathrm{m})$ & 372 & 511 & 365 \\
Basin shape index $(\mathrm{Bs})$ & 2.8 & 3.04 & 5.8 \\
Asymmetric factor $(\mathrm{Af})$ & 61.4 & 49.7 & 47.2 \\
Total length $(\mathrm{km})$ & 2242.25 & 1351.35 & 1584.09 \\
Drainage density $\left(\mathrm{km} / \mathrm{km}^{2}\right)$ & 6.43 & 6.19 & 6.24 \\
Hierarchical anomaly index $(\Delta \mathrm{a})$ & 1.87 & 2.37 & 1.35 \\
\hline
\end{tabular}

\section{Discussion}

The merging points of the individual fold segments have major effects on the pattern of the regional drainage system. The hypsometric curves of the three basins have a typical shape of a mature stage with a slight rejuvenation in the lower and middle parts of the curves (Fig. 7); they are the same as recognized by Bahrami (2013) in Iran within Zagros Range. This is attributed to a local uplift linked to the normal and thrust faults.

The hypsometric curve lines are almost similar in the three basins indicating mainly old stage basins (Fig. 7). However, in Dwaine and Hijran basins, the curve leaves the relative area $(\mathrm{a} / \mathrm{A})$ at a value of about 0.2 , whereas that of Hareer leaves the relative area $(\mathrm{a} / \mathrm{A})$ at a value of about 0.1 . Moreover, the three curves leave the old stage and run in between old and mature stages for about $70 \%$ of their relative areas $(\mathrm{a} / \mathrm{A})$ and join the mature stage at the end of their relative areas, indicating that they are already in mature stages. The values of the Af are shown in Table 1. The tilting in the right side is clear in Hareer basin due to the impact of the main thrust fault along the southwestern limb of Hareer anticline (Figs. 3 and 5).

Seven-order streams is recognized in the study area following Strahler (1957) method (Table 2). Regarding the relative parameters of the hierarchal analysis of the hydrograph network, the reach of order is seven for the three basins, showing well-organized drainage. The values of Hat and $\Delta \mathrm{a}$ indices are given in Table 3. The Hat values of the basins range from 7014 in Hijran basin to 13,615 in Hareer basin. The data presented in Table 3 shows that in basins with higher Hat values, the number of the streams with low order (i.e., 1) which joins with higher-order streams (i.e., 6 and 7) is considerably high. The values of $\Delta \mathrm{a}$ are $1.87,2.37$, and 1.35 in Hareer, Dwaine, and Hijran basins, respectively (Table 1). These data also indicate active tectonics in the studied three basins. Such activity was also detected in Sicilian side of the Messina Strait (NE Sicily, Italy) (Guarnieri and Pirrotta 2008) and in southern Apennines, Italy (Santangelo et al. 2013).

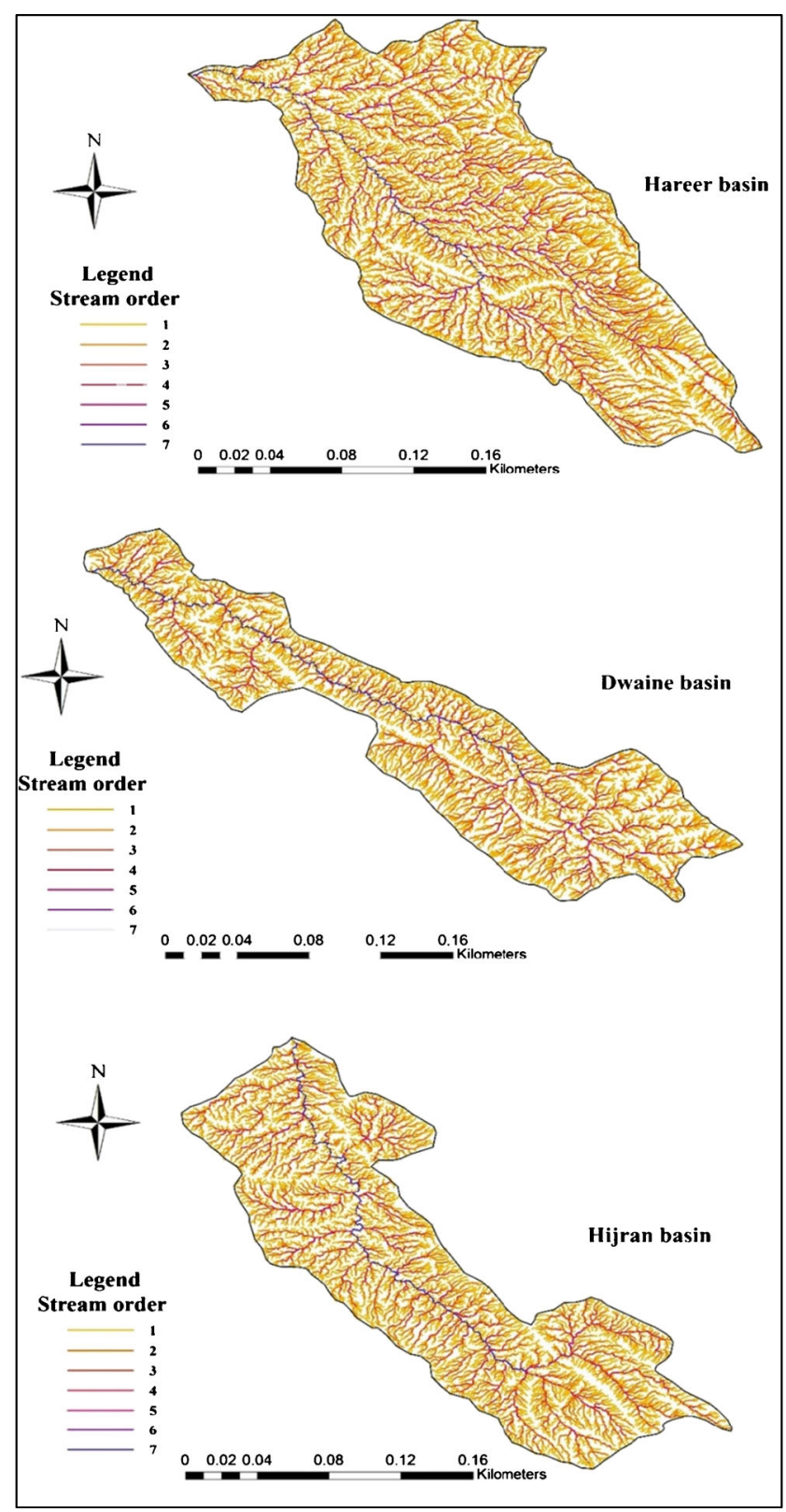

Fig. 8 Drainage map of basins. The hydrographic network is represented according to the Strahler (1957) ordering system

The growth of the folds becomes younger northeastwards in the study area. Therefore, the fold growth has effected on the drainage pattern in the following forms: (1) decrease in the relief of the topographic profile along the fold crest in Dwaine and Hijran drainage basins, (2) development of younger tributaries along the fold growth direction, (3) development of characterized asymmetry drainage pattern and hypsometric curve index, and (4) the values of hierarchy of the parameters of the hydrographic network indicate a poorly developed hierarchy. Variations in the direction of hinge lines along the Hareer anticline are very clear. This is another indication for the lateral growth of the fold. Such indication was also 
Table 2 Stream order, number of stream order, stream length, and area (for Hareer, Dwaine, and Hijran basins, respectively)

Stream order (U) No of streams (NU) Stream length $(\mathrm{km})$ Area $\left(\mathrm{km}^{2}\right)$

\begin{tabular}{|c|c|c|c|}
\hline \multicolumn{4}{|c|}{ Hareer } \\
\hline 1 & 7248 & 1.79 & 2.37 \\
\hline 2 & 1440 & 5.13 & 1.03 \\
\hline 3 & 306 & 2.15 & 2.79 \\
\hline 4 & 73 & 4.92 & 7.76 \\
\hline 5 & 18 & 2.47 & 4.006 \\
\hline 6 & 4 & 5.18 & 7.73 \\
\hline 7 & 1 & 2.24 & 3.48 \\
\hline \multicolumn{4}{|c|}{ Dwaine } \\
\hline 1 & 4418 & 1.21 & 2.51 \\
\hline 2 & 925 & 5.29 & 8.65 \\
\hline 3 & 225 & 1.53 & 2.47 \\
\hline 4 & 50 & 4.76 & 8.14 \\
\hline 5 & 9 & 1.42 & 2.37 \\
\hline 6 & 2 & 4.65 & 7.604 \\
\hline 7 & 1 & 1.35 & 2.18 \\
\hline \multicolumn{4}{|c|}{ Hijran } \\
\hline 1 & 5170 & 1.24 & 1.79 \\
\hline 2 & 14,047 & 4.52 & 7.15 \\
\hline 3 & 230 & 1.66 & 2.65 \\
\hline 4 & 48 & 5.86 & 9.36 \\
\hline 5 & 10 & 1.28 & 2.06 \\
\hline 6 & 2 & 2.62 & 4.208 \\
\hline 7 & 1 & 1.58 & 2.53 \\
\hline
\end{tabular}

mentioned in Zagros Range at the northeastern part of Iraq (Bretis et al. 2011).

The fold growth in the study area has not developed from a single involved fold but lateral linkage of several different fold segments. Such examples are recorded from Qara Dagh anticline (Sissakian et al. 2018) which is located southeast of the current study area.

The fold growth has impact on the topography of the study area and drainage pattern. The fold growth's control on the drainages anomaly is validated by linear regressions (directly proportional) for $\mathrm{AF}, \mathrm{Bs}-\Delta \mathrm{a}$, and $\mathrm{Bl} / \mathrm{Bw}-\Delta$ a pairs, revealing that the drainage anomaly of basins increases with increasing the length of the basins (Table 2). Mature stage of the hypsometry curve is also connected with the shape of the basin.

The lateral fold growth in the study area has resulted in variations of morphometric parameters of the basins formed within the four folds: Hareer, Shakrook, Safin, and Pirmam. Therefore, the folds became younger, as their growth is considered from northeast to southwest demonstrating that the deformation front is migrating from the Suture Zone, which is located northeast of the study area. The folds' variations also have considerable effects on the differences of drainage system patterns and anomalies. This effect is clear in the shape of Dwaine and Hijran basins, because they are located between two steep anticlines and synclines. Parallel and trellis drainage patterns are developed in the two basins; consequently, the hierarchical anomaly number is increased and hence the $\Delta \mathrm{a}$ value is increased too, whereas, in Hareer basin, especially when the stream flows westwards of Shakrook anticline (Figs. 1 and 4), the basin becomes very wide (Fig. 5). This is attributed to the exposed soft rocks (Kolosh and Gercus formations) as compared to the hard rocks of Bekhme Formations which form the carapace of all mountains (anticlines) in the study area. Such case was identified in NW Zagros (Talling and Sowter 1999; Zhang et al. 2006). Moreover, the stream east of Shakrook plunge area is very narrow due to a large thrust fault (Fig. 4) which is very clearly recognized in the field.

Variation in the fold growth from NW to the SE allows the drainage basin to adjust the growth. This adjustment is clearly shown by the movement of the trunk river towards northwest of the growing limb. Moreover, the basin shape is also an indication for tectonic activity; an elongated basin indicates high tectonic activity. The three studied basins have elongated shapes (Fig. 8), indicating high tectonic activity in the studied basins. Such indication is also noticed and confirmed from different streams and basins in Italy (Avena et al. 1967).

The amplitude of the folds increases from north to south. This is clear in Safin anticline which has the highest amplitude followed by Shakrook and Hareer. However, Pirmam anticline shows lower amplitude than Safin, although it is located south of Safin anticline. This is attributed most probably to (1) the type of the exposed rocks in Pirmam anticline which are well-bedded limestone of the Pila Spi Formation underlain by soft clastics of Gercus and Kolosh formations (Fig. 4); (2) Pirmam anticline represents the last fold in the High Folded Zone as moving southwards, which means it has received less compressional forces as compared to Safin anticline; and (3) Pirmam anticline has received more compressional forces than Shakrook and Hareer, this is confirmed by the existence of two hanging synclines northwards of Safin anticline (Fig. 4). Both synclines are extensively faulted (Fig. 6), indicating extensive compressional forces which have developed the hanging synclines.

\section{Conclusions}

From the fluvial morphometric study, we have recognized that there is a structural control over the development of the studied three drainage basins. The tectonic forces have played a role in shaping the land forms 
Table 3 Stream junctions $(\mathrm{i} \rightarrow \mathrm{j}$ ), hierarchical anomaly number of every stream junction $(\mathrm{Hai} \rightarrow \mathrm{j})$, number of streams for each junction $(\mathrm{Nsi} \rightarrow \mathrm{j}$ ), $\mathrm{Hai} \rightarrow \mathrm{j}$ by Nsi $\rightarrow \mathrm{j}$, and hierarchical anomaly number of the whole basin (Hat) in the studied three basins

\begin{tabular}{|c|c|c|c|c|c|c|c|c|c|}
\hline $\mathrm{i} \rightarrow \mathrm{j}$ & $\begin{array}{l}\mathrm{Hai} \rightarrow \mathrm{j} \\
\mathrm{A}\end{array}$ & $\begin{array}{l}\mathrm{Nsi} \rightarrow \mathrm{j} \\
\mathrm{B}\end{array}$ & $\begin{array}{l}\text { Hareer } \\
\mathrm{A} \times \mathrm{B}\end{array}$ & $\begin{array}{l}\mathrm{Hai} \rightarrow \mathrm{j} \\
\mathrm{A}\end{array}$ & $\begin{array}{l}\mathrm{Nsi} \rightarrow \mathrm{j} \\
\mathrm{B}\end{array}$ & $\begin{array}{l}\text { Dwaine } \\
\mathrm{A} \times \mathrm{B}\end{array}$ & $\begin{array}{l}\mathrm{Hai} \rightarrow \mathrm{j} \\
\mathrm{A}\end{array}$ & $\begin{array}{l}\mathrm{Nsi} \rightarrow \mathrm{j} \\
\mathrm{B}\end{array}$ & $\begin{array}{l}\text { Hijran } \\
\mathrm{A} \times \mathrm{B}\end{array}$ \\
\hline $1 \rightarrow 2$ & 0 & 5279 & 0 & 0 & 3481 & 0 & 0 & 4398 & 0 \\
\hline $1 \rightarrow 3$ & 1 & 952 & 952 & 1 & 428 & 428 & 1 & 370 & 370 \\
\hline $1 \rightarrow 4$ & 3 & 580 & 1740 & 3 & 263 & 789 & 3 & 188 & 564 \\
\hline $1 \rightarrow 5$ & 7 & 277 & 1939 & 7 & 79 & 553 & 7 & 97 & 679 \\
\hline $1 \rightarrow 6$ & 15 & 77 & 1155 & 15 & 37 & 555 & 15 & 24 & 360 \\
\hline $1 \rightarrow 7$ & 31 & 83 & 2573 & 31 & 130 & 4030 & 31 & 93 & 2883 \\
\hline $2 \rightarrow 3$ & 0 & 1036 & 0 & 0 & 787 & 0 & 0 & 942 & 0 \\
\hline $2 \rightarrow 4$ & 2 & 158 & 316 & 2 & 36 & 72 & 2 & 53 & 106 \\
\hline $2 \rightarrow 5$ & 6 & 118 & 708 & 6 & 29 & 174 & 6 & 35 & 210 \\
\hline $2 \rightarrow 6$ & 14 & 55 & 770 & 14 & 15 & 210 & 14 & 3 & 42 \\
\hline $2 \rightarrow 7$ & 30 & 73 & 2190 & 30 & 58 & 1740 & 30 & 14 & 420 \\
\hline $3 \rightarrow 4$ & 0 & 234 & 0 & 0 & 169 & 0 & 0 & 185 & 0 \\
\hline $3 \rightarrow 5$ & 4 & 32 & 128 & 4 & 6 & 24 & 4 & 17 & 68 \\
\hline $3 \rightarrow 6$ & 12 & 17 & 204 & 12 & 2 & 24 & 12 & 3 & 36 \\
\hline $3 \rightarrow 7$ & 28 & 23 & 644 & 28 & 48 & 1344 & 28 & 25 & 700 \\
\hline $4 \rightarrow 5$ & 0 & 20 & 0 & 0 & 29 & 0 & 0 & 26 & 0 \\
\hline $4 \rightarrow 6$ & 8 & 10 & 80 & 12 & 3 & 24 & 8 & 1 & 8 \\
\hline $4 \rightarrow 7$ & 24 & 7 & 168 & 24 & 18 & 432 & 24 & 21 & 504 \\
\hline $5 \rightarrow 6$ & 0 & 15 & 0 & 0 & 4 & 0 & 0 & 6 & 0 \\
\hline $5 \rightarrow 7$ & 16 & 3 & 48 & 16 & 5 & 80 & 16 & 4 & 64 \\
\hline $6 \rightarrow 7$ & 0 & 2 & 0 & 0 & 2 & 0 & 0 & 2 & 0 \\
\hline Hat & & & 12,971 & & & 10,479 & & & 7014 \\
\hline
\end{tabular}

during the geologic history. However, the role of the rock types cannot be ignored, since wide streams are developed in weak rocks, whereas in hard rocks, narrow streams are developed with steep banks. Using the studied geomorphological indices, it can be shown that Hareer, Shakrook, Safin, and Pirmam anticlines and the existing faults, especially thrust faults, have played a big role on the shaping of the streams of the three basins. Not only the anticline effect but also the syncline effects on the shaping of the streams and trunk of channels are clear. The result of the impact is clear on the increasing of the hierarchical anomaly number in the orders 6 and 7, because of increasing order one. The lateral growth of the folds has effected on the increasing of the anomaly in the streams of orders 6 and 7. The hypsometric curves of the three basins indicate that the basins are of old stage; however, they have passed to a mature stage in their ends. The Bs and Hat values in Hareer, Dwaine, and Hijran basins indicate that the basins exhibit low, medium, and high tectonic activity, respectively.
Funding Open access funding provided by Lulea University of Technology.

Open Access This article is licensed under a Creative Commons Attribution 4.0 International License, which permits use, sharing, adaptation, distribution and reproduction in any medium or format, as long as you give appropriate credit to the original author(s) and the source, provide a link to the Creative Commons licence, and indicate if changes were made. The images or other third party material in this article are included in the article's Creative Commons licence, unless indicated otherwise in a credit line to the material. If material is not included in the article's Creative Commons licence and your intended use is not permitted by statutory regulation or exceeds the permitted use, you will need to obtain permission directly from the copyright holder. To view a copy of this licence, visit http://creativecommons.org/licenses/by/4.0/.

\section{References}

Abdulnaby W (2018) Chapter 4: Structural geology and Neotectonics of Iraq, Northwest Zagros. In: Tectonic and Structural Framework of the Zagros Fold-Thrust Belt. https://doi.org/10.1016/B978-0-12815048-1.00004-4 
Abrahams AD (1984) Channel networks: a geomorphological perspective. Water Resour Res 20:161-118

Al-Brifkani M (2016) Determining regional shortening of the Taurus Foreland folds-Northern Iraq. Int J Eng Res Appl 6(1 1, (Part -2)): $58-65$

Alipoor R, Poorkermani M, Zare M, El Hamdouni R (2011) Active tectonic assessment around Rudbar Lorestan dam site, High Zagros Belt (SW of Iran). Geomorphol J 128:1-14

Al-Shali RA (1992) Balancing cross section from the simple folded zone of Iraq. Unpublished M.Sc. Thesis. University of Mosul, Mosul

Avena GC, Giuliano G, Lupia Palmieri E (1967) Sulla valutazione quantitativa della gerarchizzazione ed evoluzione dei reticoli fluviali. Boll Soc Geol Ital 86:781-796

Bahrami S (2013) Analyzing the drainage system anomaly of Zagros basins: implications for active tectonics. Tectonophysics 608:914 928

Bretis B, Bartl N, Grasemann B (2011) Lateral fold growth and linkage in the Zagros fold and thrust belt (Kurdistan, NE Iraq). Basin Research 23 , p. $615-630$

Bull WB (2007) Tectonic geomorphology of mountains: a new approach to paleoseismology. Blackwell, Malden

Burbank DW, Anderson RS (2001) Tectonic geomorphology. Blackwell Science, Malden

Cudennec C, Fouad Y (2006) Structural patterns in river network organization at both infra- and supra-basin levels: the case of a granitic relief. Earth Surf Process Landf 31:369-381

Deffontaines B, Chorowicz J (1991) Principles of drainage basin analysis from multisource data: application to the structural analysis of the Zaire Basin. Tectonophysics 194:237-263

Delcaillau B, Carozza JM, Laville E (2006) Recent fold growth and drainage development, the Janauri and Chandigarh anticlines in the Siwalik foothills, Northwest India. Geomorphology 76:241-256

Devi RKM, Bhakuni SS, Bora PK (2011) Tectonic implication of drainage set-up in the Sub-Himalaya: a case study of Papumpare district, Arunachal Himalaya, India. Geomorphology 127:14-31

El-Hamdouni R, Irigaray C, Fernandez T, Chacón J, Keller EA (2008) Assessment of relative active tectonics, southwest border of Sierra Nevada (southern Spain). Geomorphology 96:150-173

Elias Z (2015) The neotectonic activity along the lower Khazir River by using SRTM image and geomorphic indices. Earth Sci J 1:50-58

Fouad SF (2012) Tectonic Map of Iraq, scale 1:1000000, 3rd edition. Iraq Geological Survey Publications, Baghdad, Iraq

Guarnieri P, Pirrotta G (2008) The response of drainage basins to the late Quaternary tectonics in the Sicilian side of the Messina Strait (NE Sicily). Geomorphology 95:260-273

Horton RE (1945) Erosional development of streams and their drainage basins; hydrophysical approach to quantitative morphology. Geol Soc Am Bull 56:275-370

Jackson J, Van Dissen R, Berryman K (1998) Tilting of active folds and faults in the Manawatu region, New Zealand: evidence from surface drainage patterns, New Zealand. J Geol Geophys 41:377-385

Jamieson SSR, Sinclair HD, Kirstein LA, Purves RS (2004) Tectonic forcing of longitudinal valleys in the Himalaya, morphological analysis of the Ladakh batholith North India. Geomorphology 58:49-65

Keller EA, Pinter N (2002) Active tectonics: earthquakes, uplift, and landscape, 2nd edn. Prentice Hall, Upper Saddle River, p 359
Marouf NZ (1999) Dynamic evolution of sedimentary basin in northern Iraq and hydrocarbon formation, migration and entrapment. Unpublished Ph. D. Thesis. University of Baghdad, Baghdad

McQuarrie N, Stock JM, Verdel C, Wernicke BP (2003) Cenozoic evolution of Neotethys and implication for the causes of plate motions. Geophys Res Lett 30:2036

Oberlander TM (1985) Origin of drainage transverse to structures in orogens. In: Morisawa M, Hack JT (eds) Tectonic Geomorphology. Allen and Unwin, Boston, pp 155-182

Omer A, Lawa F, Sulaiman S (2015) Tectonostratigraphic and structural imprints from balanced sections across the north-western Zagros fold-thrust belt, Kurdistan region, NE Iraq. Arab J Geosci 8:81078129

Ramsey LA, Walker RT, Jackson J (2008) Fold evolution and drainage development in the Zagros mountains of Fars province, SE Iran. Basin Res 20:23-48

Reif D, Decker K, Grasemann B, Peresson H (2012) Fracture patterns in the Zagros fold-and-thrust belt, Kurdistan region of Iraq. Tectonophysics 576-577:46-62

Santangelo M, Gioia D, Cardinali M, Guzzetti F, Schiattarella M (2013) Interplay between mass movement and fluvial network organization: an example from southern Apennines, Italy. Geomorphology 188:54-67

Simoni A, Elmi C, Picotti V (2003) Late Quaternary uplift and valley evolution in the Northern Apennines Lamone Catchment. Quat Int 101-102:253-267

Sissakian VK (1997) Geological map of Arbeel and Mahabad quadrangles, scale 1: 250000. Iraq Geological Survey Publications, Baghdad

Sissakian VK, Fouad SF (2012) Geological Map of Iraq scale 1:1000000, 4th edition. Iraq Geological Survey Publications, Baghdad, Iraq

Sissakian VK, Fouad SF (2014) Geological map of Erbil quadrangle, scale 1:250 000, 2nd edn. Iraq Geological Survey Publications, Baghdad

Sissakian VK, Youkhanna RY (1979) Report on the regional geological 734 mapping of Erbil-Shaqlawa-Koi Sanjaq-Raidar area. Iraq Geological Survey Library Report No 975, Baghdad, Iraq

Sissakian VK, Amin RM, Mohammed JG (2018) The lateral growth of Qara Dagh anticline. A tectonic-geomorphological study, South of Sulaimaniyah City, Ne Iraq. Iraqi Bul Geol Min 14(2):31-47 Baghdad, Iraq

Strahler AN (1952) Hypsometric (area-altitude) analysis of erosional topography. Geol Soc Am Bull 63:1117-1142

Strahler AN (1957) Quantitative analysis of watershed geomorphology. Trans Am Geophys Union 38:913-920

Sung O, Chen YC (2004) Geomorphic evidence and kinematic model for quaternary transfer faulting of the Pakuashan anticline, central Taiwan. J Asian Earth Sci 24:389-404

Talling PJ, Sowter MJ (1999) Drainage density on progressively tilted surfaces with different gradients, Wheeler Ridge, California. Earth Surf Process Landf 24:809-824

Tatar M, Hatzfeld D, Martinod J, Walpersdorf A, Ghafori-Ashtiany M, Chery J (2002) The present day deformation of the central Zagros from GPS measurements. Geophys Res Lett 29:1927

Zhang HP, Liu SF, Yang N, Zhang YQ, Zhang GW (2006) Geomorphic characteristics of the Minjiang Drainage Basin (eastern Tibetan Plateau) and its tectonic implications: new insights from a digital elevation model study. Island Arc 15:239-250 